\title{
A 3-month, double-blind, controlled trial of feeding with sucrose polyester in human volunteers
}

\author{
Sean M. Kelly*, Maria Shorthouse, Josephine C. Cotterell, Alex M. Riordan, Alison J. Lee, \\ David I. Thurnham $\dagger$, Rudolf Hanka and John O. Hunter $\dagger$ \\ Department of Gastroenterology, Addenbrooke's Hospital, Cambridge CB2 2QQ, UK
}

(Received 26 February 1997 - Revised 29 December 1997 - Accepted 30 January 1998)

\begin{abstract}
Sucrose polyester (SPE) is a tasteless, odourless substance which reduces plasma cholesterol concentrations and may therefore be valuable as a fat substitute in human foodstuffs. It has recently been approved for use in snack foods by the United States Federal Drug Administration. The current study was designed to investigate its effects on gastrointestinal physiology and nutrient absorption in human subjects. A 6-month $(2 \times 3$-month periods $)$ double-blind, placebocontrolled, randomized, cross-over trial of SPE and control fat was performed in healthy freeliving volunteers. Subjects consumed 20-40 g of SPE daily (mean $26 \cdot 8$ (SE 6.8) g) which reduced the intake of total and saturated fat but had no effect on energy intake or body weight. Plasma cholesterol and triacylglycerols were reduced. The frequency of bowel movements and their urgency were increased and anal leakage occured in $7.2 \%$ of subjects. Abdominal pain was more frequent in subjects receiving SPE and was significantly greater than in the control group after 8 weeks feeding. The plasma concentrations of vitamin $\mathrm{E}$ and six carotenoids were significantly reduced. Routine haematology and biochemistry, other vitamins, intestinal biopsies, bile-salt retention, rectal prostaglandins, fractional $\mathrm{Ca}$ absorption and aminopyrine metabolism were unaffected. The ingestion of foods containing 20-40 g SPE daily provoked significant gastrointestinal problems. This intake is greater than that to be expected from the use of SPE in savoury snack foods, for which it has been approved by the United States Federal Drug Administration. However, the favourable effects on lipid profiles must be balanced against the reduction in the concentrations of vitamins and carotenoids, as these compounds may have beneficial effects on health through protection from free-radical oxidative stress.
\end{abstract}

Sucrose polyester: Absorption: Cholesterol

Sucrose polyester (SPE) is a tasteless, odourless, nonabsorbable fat-like substance synthesized from sucrose and fatty acid methyl esters. It interferes with the absorption of dietary cholesterol from the gut and studies in man have shown that it may lower plasma cholesterol (Jandacek, 1984, Mellies et al. 1985). In obese subjects it may lower dietary energy intake and thereby promote weight loss (Glueck et al. 1982). SPE thus appears likely to have considerable commercial potential as a fat-substitute, particularly as earlier studies had suggested that its ingestion had little effect on bowel function (Bergholtz et al. 1991) and that vitamin $\mathrm{E}$ was the only fat-soluble vitamin whose absorption was significantly impaired (Crouse \& Grundy 1979). Early in 1996 SPE was approved by the United States Federal Drug Administration for use in savoury snack foods.
In the light of this decision it seemed important to report our studies on the effects of chronic administration of SPE on gastrointestinal physiology and nutrient absorption in man.

\section{Methods \\ Subjects and study design}

This was a 6-month, two-period, double-blind, cross-over trial. Healthy subjects aged 18 to 65 years were recruited. They were paid expenses of $£ 50-100$ depending on the complexity of the special investigation they chose to undergo, and all trial food items were supplied free. Most volunteers were health professionals at Addenbrooke's Hospital or their close relatives. The studies were approved

\footnotetext{
Abbreviations: P:S, polyunsaturated : saturated fat; SCFA, short-chain fatty acid; SPE, sucrose polyester; TAG, triacylglycerol; WGTT, whole-gut transittime.

* Present address: York District General Hospital, York YO3 7HE, UK.

$\uparrow$ Present address: University of Ulster, Coleraine, Co. Londonderry BT52 1SA, UK.

\$Corresponding author: Dr John O. Hunter, fax 01223211443
} 
by the Cambridge Local Research Ethics Committee and informed consent was given by all subjects. Females were required to use a reliable method of contraception. Subjects were randomized to receive either foods containing SPE or identically packed control food, for a period of 3 months followed by a further 3 months on the alternative food.

All SPE was produced by Unilever Research Laboratory pilot plant, Vlaardingen, The Netherlands. Four types of SPE were used, described as L, H1, inES and H2. L is SPE oil, whilst the other three are solid fats at room temperature, having melting points of $35-45^{\circ}$. Analytical specifications and the typical fatty acid composition are available on request. The majority of foods contained $\mathrm{L}$ and $\mathrm{H} 2$ types; H1 was used only in chocolate, inES in only one batch of milk (Table 1). Control products contained fats (triacylglycerol, TAG) having properties comparable to those of the SPE types in the test products. SPE was incorporated into the following foods: chips, beefburgers, meat pies, sausages, sausage rolls, fruit pies, milk, margarine, salad cream, fruit dessert, processed cheese, biscuits, peanut butter, cake, crisps, chocolate spread and chocolate bars.

Before starting the trial, subjects discussed with a dietitian how to achieve their daily lipid target of 20-40 $\mathrm{g}$ of SPE or TAG. One unit of approximately $5 \mathrm{~g}$ of SPE or TAG could be identified in a single portion of a food product. The daily diet could then be composed from available foods so that 4-8 units/d were consumed. Volunteers were then free to choose those trial foods which fitted most closely with their normal eating patterns. A computer system was installed which enabled each subject's intake to be closely monitored. Products were labelled with a bar-code which identified the food product, the period of the cross-over trial and the individual food portion.

Table 1. Information on sucrose polyester food products

\begin{tabular}{llllr}
\hline & & \multicolumn{3}{c}{ SPE type (\%) } \\
\cline { 3 - 5 } Product & & H1 & H2 & $\mathrm{L}$ \\
\hline Bakery products & $4 \cdot 2$ & 0 & 80 & 20 \\
$\quad$ Biscuits & $5 \cdot 4$ & 0 & 50 & 50 \\
Cake & $6 \cdot 0$ & 0 & 100 & 0 \\
Crisps & $6 \cdot 7$ & 0 & 100 & 0 \\
Sausage rolls & $5 \cdot 0$ & 0 & 100 & 0 \\
Fruit pie & $7 \cdot 4$ & 0 & 100 & 0 \\
Meat pie & & & & \\
Dairy products & $5 \cdot 3$ & 0 & 100 & 0 \\
Milk & $4 \cdot 2$ & 0 & 100 & 0 \\
Fruit dessert & $3 \cdot 7$ & 0 & 0 & 100 \\
Processed cheese & & & & \\
Fats & $4 \cdot 3$ & 0 & 25 & 75 \\
Margarine & & & & \\
Food products & $4 \cdot 4$ & 100 & 0 & 0 \\
Chocolate & $3 \cdot 7$ & 0 & 0 & 100 \\
Chocolate spread & $4 \cdot 8$ & 0 & 0 & 100 \\
Peanut butter & $3 \cdot 1$ & 0 & 0 & 100 \\
Salad cream & $4 \cdot 7$ & 0 & 100 & 0 \\
Beefburger & $4 \cdot 6$ & 0 & 100 & 0 \\
Sausage & $5 \cdot 0$ & 0 & 100 & 0 \\
French fries & & & & \\
\hline
\end{tabular}

SPE, sucrose polyester.

\section{Study procedures}

The following investigations were performed throughout the study period.

Dietary assessment. A dietary assessment was completed before commencement of the study and again during the final week of each 12-week period. Subjects recorded a full food diary for 4 days. The diary data were analysed using a standardized computer program (UNIDAP, Unilever plc, Blackfriars, London, UK). The parameters assessed included energy $(\mathrm{kJ} / \mathrm{d})$, polyunsaturated : saturated fat ratio $(\mathrm{P}: \mathrm{S})$, cholesterol $(\mathrm{mg} / \mathrm{d})$, fibre $(\mathrm{g} / \mathrm{d})$, vitamin A $(\mathrm{mg}$ retinol/d), vitamin $\mathrm{D}(\mu \mathrm{g} / \mathrm{d}), \mathrm{Ca}(\mathrm{mg} / \mathrm{d}), \mathrm{Fe}(\mathrm{mg} / \mathrm{d}), \mathrm{SPE}$ $(\mathrm{g} / \mathrm{d})$ and total fat $(\mathrm{g} / \mathrm{d})$.

Dietary intake was also monitored by computer analysis of the foods distributed to volunteers which were marked with specific barcodes.

Medical questionnaire. At weeks 4, 8 and 12 of each 3month period, subjects completed a questionnaire when symptoms were scored by categories and recorded. These included bowel frequency, urgency associated with bowel movement, abdominal discomfort, flatulence, bloating, anal leakage and rectal irritation. At the preliminary medical examination, any subjects suffering any of the above symptoms were excluded.

\section{Investigations}

Haematology and biochemistry. The following investigations were performed before and after 4, 8 and 12 weeks of each 3-month period. Blood tests were processed routinely by the Departments of Haematology and Biochemistry at Addenbrooke's Hospital. These included body weight, full blood count, prothrombin time, urea and electrolytes, liver function tests, cholesterol, TAG, HDL and LDL. Before and after 12 weeks of each period, blood samples were also taken to assay vitamins A, D, E and carotenoids, as well as the percentages of essential fatty acids in plasma phospholipid.

Colonic function. Before and after 12 weeks in each period, all stools passed over a $48 \mathrm{~h}$ period were collected for measurement of faecal weight, whole gut transit time (WGTT), faecal bile acids and faecal short chain fatty acids (SCFA). Random stool samples were taken occasionally from all subjects to check for the presence or absence of SPE.

Urine. All subjects completed a $24 \mathrm{~h}$ urine collection before and after 12 weeks for measurement of D-glucaric acid, a marker of hepatic enzyme induction.

Specialized investigations. Each subject also underwent one of the following investigations at the end of each diet period: rectal biopsy and histological examination, intestinal permeability study, bile-salt retention study, jejunal biopsy and histological examination, measurement of rectal prostaglandins $\left(\mathrm{PGE}_{2}\right.$ and 6-keto- $\left.\mathrm{F}_{1} \alpha\right)$ or determination of $\mathrm{Ca}$ absorption and aminopyrine metabolism.

\section{Analytical methods}

\section{Plasma vitamins and carotenoids}

Vitamin D was measured as 25-hydroxycholecalciferol by HPLC after extraction from plasma (Hollis \& Frank, 1985). 
Vitamins $\mathrm{A}$ and $\mathrm{E}$ were measured as retinol and $\alpha$-tocopherol respectively. Plasma lipids were extracted into hexane and analysed by reverse phase HPLC (Catignani \& Bieri, 1983). Carotenoids were measured by HPLC after extraction with heptane (Thurnham et al. 1988). Essential fatty acids were determined by the method of Manku et al. (1983).

D-Glucaric acid. D-Glucaric acid in urine was measured by an enzymic method after boiling the sample of urine (Juno \& Pergande, 1984).

Colonic function. SCFA and bile acid were analysed in faecal samples as follows: $3 \mathrm{~d}$ collections of faeces were homogenized and a portion freeze-dried. For measurement of SCFA $1 \mathrm{~g}$ samples of the freeze-dried faeces were acidified and extracted with diethylether and SCFA measured by GC (MacFarlane et al. 1986). Bile acids were measured by capillary GC after hydrolysis and derivatization (Grundy et al. 1965).

Whole-gut transit-time. WGTT was measured using the method described by Cummings \& Wiggins (1976). Subjects ingested capsules containing radio-opaque markers at 08.00 hours on three consecutive mornings leading up to the day of study. The first stool passed on that day was collected separately and the time recorded. This stool was then X-rayed and the different markers counted enabling WGTT to be calculated.

\section{Specialized investigations}

Rectal prostaglandins. Rectal prostaglandins were measured by inserting an $8 \mathrm{~cm}$ long dialysis bag of 'Visking' $8 / 32$ tubing containing $120 \mathrm{mmol} / 1 \mathrm{Na}^{+}, 120 \mathrm{mmol} / \mathrm{l} \mathrm{Cl}^{-}$, $30 \mathrm{mmol} / 1 \mathrm{~K}^{+}$and $30 \mathrm{mmol} / \mathrm{l} \mathrm{HCO}_{3}^{-}(\mathrm{pH} 8 \cdot 1$ ), mounted on a catheter, into the rectum to a position $120 \mathrm{~mm}$ above the anus. Each bag was left in position for $1 \mathrm{~h}$ and the volume of dialysate was then measured and frozen at $-20^{\circ}$ until analysed. Prostaglandins $\mathrm{E}_{2}$ and 6-keto- $\mathrm{F}_{1} \alpha$ in the dialysate were measured by RIA (Amersham International plc, Little Chalfont, Bucks., UK; Rampton et al. 1980).

Rectal biopsy. A standard rigid sigmoidoscope was used to obtain a biopsy for histological examination.

Intestinal permeability. Intestinal permeability was assessed by measuring urinary excretion of $\left[{ }^{14} \mathrm{C}\right]$ mannitol and ${ }^{51} \mathrm{Cr}$-EDTA (Behrens et al. 1987). The permeation of each probe molecule across the intestine is expressed as the percentage of the dose excreted into urine, and as the EDTA : mannitol ratio.

Bile salt retention. The rate of bile acid loss from the endogenous pool was measured using $\left[{ }^{75} \mathrm{Se}\right]$ tauroselcholic acid, which is an analogue of naturally occuring bile salts. Retention is measured using the retention of radioactivity over a $7 \mathrm{~d}$ period (Nyhlin et al. 1983).

Small bowel biopsy. Following an overnight fast, a gastroscope was passed into the second part of the duodenum and distal duodenal biopsies were taken. Biopsies were placed in formalin for histological examination.

Calcium absorption and liver function. Initially attempts to assess the effect of SPE on Ca absorption were performed using a ${ }^{47} \mathrm{Ca}$ method. This had to be abandoned due to difficulties in obtaining ${ }^{47} \mathrm{Ca}$ at the relevant time. Therefore a separate smaller study was set up to assess both $\mathrm{Ca}$ absorption using a ${ }^{45} \mathrm{Ca}$ method (Pecker et al. 1988) and liver microsomal function as measured by a $\left[{ }^{14} \mathrm{C}\right]$ aminopyrine breath test (Hepner \& Vesell, 1975). Twenty healthy volunteers were recruited as before. A double-blind, randomized, cross-over study was performed with 1 month on each group of foods. On entry to the study and at the end of each month, subjects underwent one of the following investigations:

Fractional calcium absorption. At $14 \mathrm{~d}$ before the first test, $92.5 \mathrm{kBq}$ of ${ }^{45} \mathrm{Ca}$ (Amersham International plc) was injected intravenously; $22 \mathrm{~h}$ later a blood sample was obtained, centrifuged, and ${ }^{45} \mathrm{Ca}$ in the serum sample measured in a scintillation counter (Beckman, High Wycombe, Bucks., UK) with automatic corrections for quenching. The value obtained was the $100 \%$ absorption value for subsequent studies. On entry to the study and at the end of each 4-week period, after an overnight fast subjects ingested $185 \mathrm{kBq}{ }^{45} \mathrm{Ca}$ added to $200 \mathrm{ml}$ milk which had been equilibrated by overnight refrigeration. Immediately before each test a serum sample was obtained to measure ${ }^{45} \mathrm{Ca}$ retained from previous tests. Subjects then swallowed the test milk and did not eat or drink for a further $4 \mathrm{~h}$. A further serum sample was taken $24 \mathrm{~h}$ later to measure ${ }^{45} \mathrm{Ca}$. Fractional $\mathrm{Ca}$ absorption was expressed as ${ }^{45} \mathrm{Ca}$ at $24 \mathrm{~h}$ after the test, divided by ${ }^{45} \mathrm{Ca}$ at 22 hours after an intravenous dose (Pecker et al. 1988).

Aminopyrine breath test. After an overnight fast subjects ingested $74 \mathrm{kBq}$ of $\left[{ }^{14} \mathrm{C}\right]$-aminopyrine (Amersham International plc) in $50 \mathrm{ml}$ water. Subjects then remained supine for $2 \mathrm{~h}$ to minimize differences in endogenous $\mathrm{CO}_{2}$ production. At the end of this period breath samples were collected in scintillation vials containing $4 \mathrm{ml} 1 \mathrm{M}$ hyamine-ethanol $(1: 1, \mathrm{v} / \mathrm{v})$ with phenolphthalein as an indicator. This resulted in the collection of $2 \mathrm{mmol} \mathrm{CO}_{2}$. Three consecutive samples were collected. Exhaled ${ }^{14} \mathrm{CO}_{2}$ was then counted in a scintillation counter with automatic correction for quenching. Cumulative excretion of ${ }^{14} \mathrm{CO}_{2}$ in the $2 \mathrm{~h}$ was calculated assuming an endogenous output of $9 \mathrm{mmol} \mathrm{CO} / 2 / \mathrm{kg}$ per h. Total radioactivity in breath ${ }^{14} \mathrm{CO}_{2}$ was expressed as a percentage of the administered dose (Hepner \& Vesell, 1975).

\section{Statistical analysis}

Statistical analyses were carried out using SPSSX and SPSSPC statistical packages. The normality of data was confirmed in cases involving parametric tests where normality of distribution was essential. Non-continuous variables from two questionnaires were either dichotomous variables or ordered categorical answers.

Differences between levels of continuous variables for the two treatments were assessed for treatment effect, period effect and first-order interactions using a method described by Armitage \& Berry (1987). Given that proper randomization was used, there was no reason to expect existence of significant order effect. In the few instances where the test for the treatment $\times$ period interaction proved statistically significant, using data from the second period would be of doubtful value. Since subjects were randomly allocated to the two treatments, the first period itself provides a perfectly valid test of the two diets. In such a case data were analysed with a two independent sample $t$ test using information from 
the first period only, as recommended by Armitage \& Berry (1987). All tests of significance were two-tailed. Differences between dichotomous variables were tested using the McNeamar test. Categorical data from questionnaires were analysed using either a sign test or a Wilcoxon matchedpairs signed-rank test as appropriate.

\section{Results}

A total of eighty-three subjects entered the trial although some assessments were not available for all subjects; fortyfour were female and thirty-nine male. This and all subsequent data in this paper represent the mean $\pm 1 \mathrm{sD}$. Seven subjects withdrew from the study for various reasons which were not associated with the diet received. Furthermore, a mistake in food labelling at the production plant resulted in five subjects receiving SPE foods during the control period, and in three others, random stool analysis revealed the presence of SPE when they were eating control foods. However, as these protocol violations would tend to reduce the differences between SPE and TAG rather than to increase them, analysis has been presented on the intent to treat basis and all seventy-six subjects were included in the analysis. The average age was $36 \cdot 0$ (SD 12.2) years.

\section{Dietary analysis}

The daily SPE consumption as calculated by dietary analysis was $26 \cdot 8$ (SD 6.8) g which correlated well with the daily consumption calculated from the bar-codes on the food wrappers of 23.9 (SD 6.3) g. Total fat and saturated fat intakes were significantly lower on the SPE diet (Table 2) whereas both the P:S ratio and Ca increased on the SPE diet. There was no statistically significant difference between the diets and the treatment periods for total energy intake.

The mean body weight at the start of the study was 68.96 (SD 12.51) kg. At 12 weeks the mean weight on control fat had risen to 69.89 (SD 12.98) $\mathrm{kg}$ whereas at 12 weeks on SPE it was 68.97 (SD 12.39) kg. The difference between control and SPE periods is significant $(P<0 \cdot 001)$ but it is apparent that no weight loss occurred in subjects eating SPE foods.

\section{Medical questionnaire}

No difference was detected between the diets for general well being, bloating, nausea and rectal irritation. However, there were significant differences in bowel function when subjects were eating SPE food and when they were eating control food. At 4, 8 and 12 weeks there was an increase in stool frequency from a median of 7 motions/week on TAG (interquartile range 6.5-10) to a median of 10/week on SPE (interquartile range $7-15, P<0.001)$. There was also an increase on SPE at 4,8 and 12 weeks in urgency, and flatulence $(P<0 \cdot 001$, Table 3$)$. Stool consistency was correspondingly less on SPE at the same times $(P<0 \cdot 001)$. Anal leakage was reported by $7 \cdot 2 \%$ of subjects whilst on SPE, but only one noticed 'specks' on a single occasion on TAG $(P=0 \cdot 028)$. Abdominal pain was reported by more subjects when on SPE than when on control fat, but the difference between the two groups only reached statistical significance at week $8(P=0 \cdot 02)$. No differences in colonic function were observed between sexes.
Table 2. Dietary assessments

\begin{tabular}{lrrrl}
\hline Nutrient & \multicolumn{1}{c}{ Mean } & SD & $n$ & $P$ value \\
\hline Energy (MJ/d) & & & & \\
Admission & $9 \cdot 51$ & $2 \cdot 60$ & 80 & \\
TAG diet & $9 \cdot 77$ & $2 \cdot 47$ & 73 & $\mathrm{NS}$ \\
SPE diet & $8 \cdot 94$ & $2 \cdot 83$ & 73 & \\
Total fat (g/d) & & & & \\
Admission & $96 \cdot 7$ & $30 \cdot 8$ & 80 & \\
TAG diet & $106 \cdot 8$ & $32 \cdot 1$ & 73 & $P<0.001$ \\
SPE diet & $84 \cdot 7$ & $29 \cdot 7$ & 73 & \\
Saturated fat (g/d) & & & & \\
Admission & $29 \cdot 2$ & $10 \cdot 7$ & 80 & \\
TAG diet & $35 \cdot 8$ & $11 \cdot 7$ & 73 & $P<0.001$ \\
SPE diet & $25 \cdot 7$ & $10 \cdot 6$ & 73 & \\
P:S ratio & & & & \\
Admission & 0.21 & 0.07 & 80 & \\
TAG diet & 0.34 & $0 \cdot 12$ & 73 & $P<0.02$ \\
SPE diet & 0.38 & 0.12 & 73 & \\
Ca (mg/d) & & & & \\
Admission & $985 \cdot 8$ & 283.5 & 80 & \\
TAG diet & $937 \cdot 4$ & $289 \cdot 7$ & 73 & $P<0.001$ \\
SPE diet & $1327 \cdot 3$ & $555 \cdot 8$ & 73 & \\
\hline
\end{tabular}

$\mathrm{P}: \mathrm{S}$, polyunsaturated:saturated fat; TAG, triacylglycerol; SPE, sucrose polyester.

\section{Haematology}

There was no significant difference between the diets for their effects on the subjects' haemoglobin, mean corpuscular volume, leucocyte count, platelets and prothrombin time.

\section{Biochemistry}

There was no difference between the diets for their effects on the subjects' urea, creatinine, $\mathrm{Na}, \mathrm{K}, \mathrm{HCI}_{3}^{-}$, glucose, bilirubin, alkaline phosphatase (EC 3.1.3.1), alanine transaminase (EC 2.6.1.2) or $\gamma$-glutamyltransferase (EC 2.3.2.2).

\section{Lipid profiles}

Cholesterol and TAG levels were lower on the SPE diet (Table 4). Both HDL and LDL were reduced significantly on SPE, with a larger effect in LDL.

No difference was detected between the effects of the diets on concentration in plasma phospholipids of linoleic acid, dihomogammalinolenic acid, palmitic acid, eicosopentanoic acid, arachidonic acid or docosahexaenoic acid. Stearic acid was reduced in subjects eating SPE, being 12.71 (SD $1 \cdot 12$ ) \% of total recovered fatty acids on SPE $v .13 \cdot 27$ (SD $1 \cdot 16) \%$ on control diet $(P=0 \cdot 005)$.

Vitamins. There was no difference between the effects of the diets with regard to vitamins A and D. However, there was a significant reduction in vitamin $\mathrm{E}$ following the SPE diet. Vitamin E was 13.51 (sD 3.25) $\mu \mathrm{g} / \mathrm{l}$ on the control diet compared to 11.66 (sD 3.01$) \mu \mathrm{g} / \mathrm{l}$ on SPE $(P \leqslant 0.001)$.

Carotenoids. Carotenoids were all reduced significantly on the SPE diet compared with the control diet (Table 5).

Colonic function. The WGTT was $50 \cdot 14$ (sD $13.58 \mathrm{~h}$ on admission and 52.81 (sD 13.44) $\mathrm{h}$ at the end of 12 weeks on the control diet. After SPE there was a significant fall to $44 \cdot 2$ (sD 12.94) h $(P<0 \cdot 001)$. Faecal weight (3 d) was $347 \cdot 6$ (sD 
Table 3. Colonic symptoms in subjects on sucrose polyester or control foods

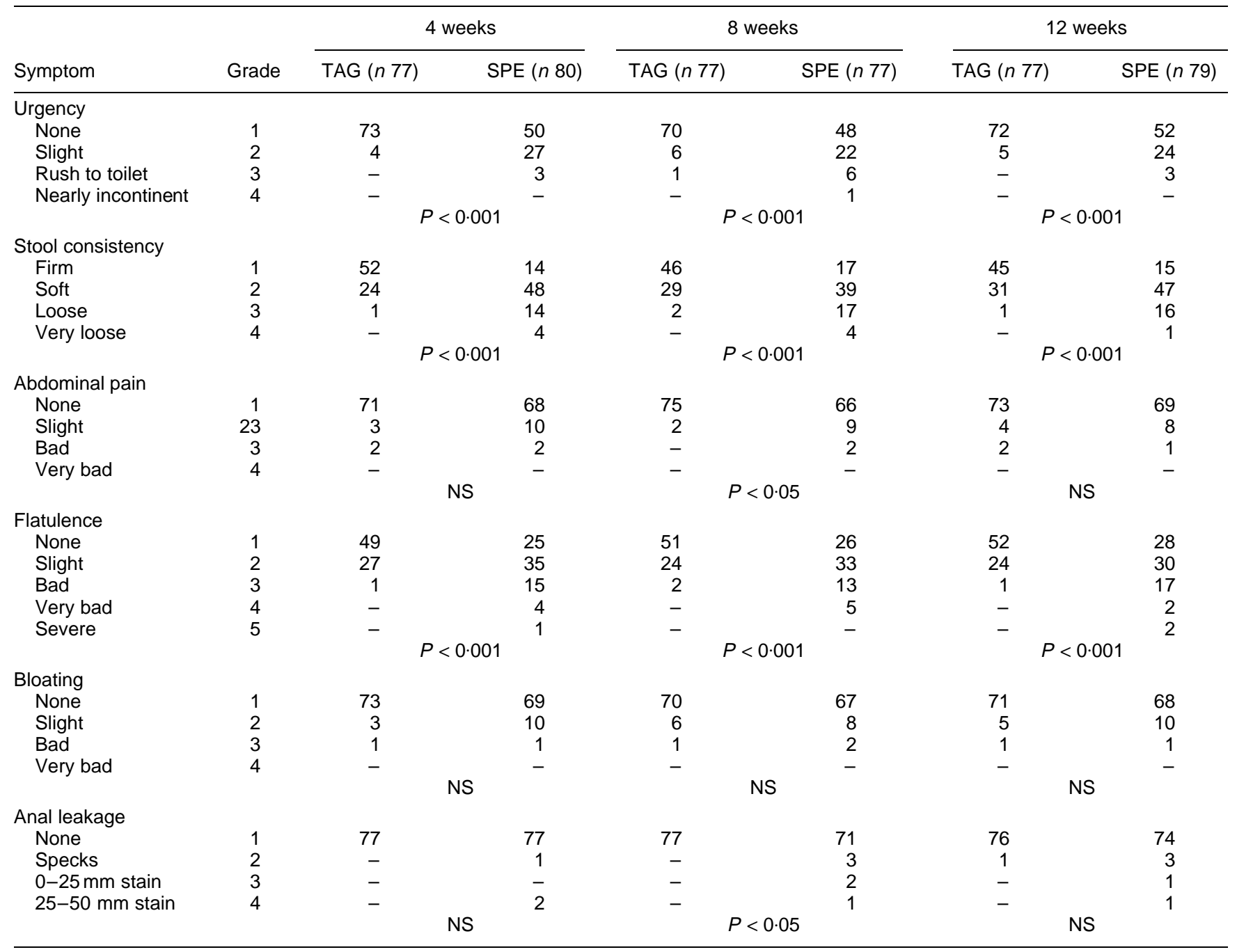

$167 \cdot 0 \mathrm{~g}$ on SPE, compared with $275 \cdot 1$ (SD 146.4) g on control diet $(P<0.005)$.

There was no change in faecal bile acids (data not shown) but there were significant changes in SCFA. Levels of acetic acid, proprionic acid and isobutyric acid all decreased on SPE (Table 6).

Urinary D-glucaric acid. There were no differences in D-glucaric acid on the SPE diet (data not shown).

\section{Special investigations}

In total, fifty subjects completed specialized investigations.

Rectal biopsy. All rectal biopsies ( $n$ 10) were normal and there was no difference to be found on light microscopy on SPE.

Small bowel biopsy. Biopsies ( $n$ 10) in seven subjects were normal throughout the study period whereas the other three subjects had mild non-specific duodenitis before entry to the study and this did not change throughout the study. No differences were observed between the SPE and control periods.

Intestinal permeability. There was no significant difference between the two diets in excretion of either mannitol or EDTA or the ratio of EDTA : mannitol ratio ( $n$ 11, data not shown).

Bile salt retention. Bile salt retention was not different between the two groups ( $n$ 9) being $21 \cdot 25$ (SD 12.76) \% on the control diet and $20 \cdot 36$ (SD 7.70) \% on SPE.

Rectal prostaglandins. There was no significant difference between levels of $\mathrm{PGE}_{2}$ or 6-ketoPGF $1 \alpha$ ( $n$ 10, data not shown).

Aminopyrine breath test and calcium absorption. In this separate study the baseline excretion of the administered ${ }^{14} \mathrm{C}$ dose was $5 \cdot 1$ (SD $\left.1 \cdot 3\right) \%$, on the control diet it was $4 \cdot 6$ (SD 1.0$) \%$ and after SPE it was $4 \cdot 4$ (SD 1.3) \%. The SPE excretion was statistically lower than baseline $(P=0.035)$ but such a change is unlikely to be of clinical significance. Fractional $\mathrm{Ca}$ absorption was not affected.

\section{Discussion}

In a prolonged dietary study of free-living volunteers it is impractical to control the diet rigidly. In this study an attempt was made to replace up to $40 \%$ of the daily dietary fat by SPE and the daily target consumption of SPE was 
Table 4. Plasma lipid concentrations after feeding with sucrose polyester and control diets

\begin{tabular}{|c|c|c|c|c|}
\hline Plasma lipid & Mean & SD & $n$ & $P$ value* \\
\hline $\begin{array}{l}\text { Cholesterol (mn } \\
\text { Admission }\end{array}$ & $5 \cdot 12$ & 1.04 & 80 & \\
\hline $\begin{array}{l}\text { TAG } \\
4 \text { weeks } \\
8 \text { weeks } \\
12 \text { weeks }\end{array}$ & $\begin{array}{l}5 \cdot 40 \\
5 \cdot 28 \\
5 \cdot 32\end{array}$ & $\begin{array}{l}0.98 \\
1.02 \\
1.00\end{array}$ & $\begin{array}{l}76 \\
76 \\
77\end{array}$ & $P<0.001$ \\
\hline $\begin{array}{l}\text { SPE } \\
4 \text { weeks } \\
8 \text { weeks } \\
12 \text { weeks }\end{array}$ & $\begin{array}{l}4 \cdot 89 \\
4.91 \\
4.92\end{array}$ & $\begin{array}{l}0.98 \\
1.09 \\
0.99\end{array}$ & $\begin{array}{l}79 \\
79 \\
79\end{array}$ & \\
\hline $\begin{array}{l}\text { Triacylglycerol } \\
\text { Admission }\end{array}$ & $1 \cdot 04$ & 0.49 & 80 & \\
\hline $\begin{array}{l}\text { TAG } \\
4 \text { weeks } \\
8 \text { weeks } \\
12 \text { weeks }\end{array}$ & $\begin{array}{l}1.11 \\
1 \cdot 16 \\
1 \cdot 09\end{array}$ & $\begin{array}{l}0.51 \\
0.55 \\
0.57\end{array}$ & $\begin{array}{l}76 \\
76 \\
77\end{array}$ & $P<0.02$ \\
\hline $\begin{array}{l}\text { SPE } \\
4 \text { weeks } \\
8 \text { weeks } \\
12 \text { weeks }\end{array}$ & $\begin{array}{l}1.11 \\
1.04 \\
0.99\end{array}$ & $\begin{array}{l}0.50 \\
0.45 \\
0.46\end{array}$ & $\begin{array}{l}79 \\
79 \\
79\end{array}$ & \\
\hline $\begin{array}{l}\mathrm{HDL}(\mathrm{mmol} / \mathrm{l}) \\
\text { Admission }\end{array}$ & $1 \cdot 26$ & 0.34 & 79 & \\
\hline $\begin{array}{l}\text { TAG } \\
4 \text { weeks } \\
8 \text { weeks } \\
12 \text { weeks }\end{array}$ & $\begin{array}{l}1.37 \\
1.36 \\
1.39\end{array}$ & $\begin{array}{l}0.38 \\
0.36 \\
0.33\end{array}$ & $\begin{array}{l}79 \\
74 \\
77\end{array}$ & $P<0.02$ \\
\hline $\begin{array}{l}\text { SPE } \\
4 \text { weeks } \\
8 \text { weeks } \\
12 \text { weeks }\end{array}$ & $\begin{array}{l}1.31 \\
1.33 \\
1.34\end{array}$ & $\begin{array}{l}0.32 \\
0.33 \\
0.34\end{array}$ & $\begin{array}{l}78 \\
77 \\
79\end{array}$ & \\
\hline $\begin{array}{l}\text { LDL (mmol/l) } \\
\text { Admission }\end{array}$ & $3 \cdot 38$ & 0.95 & 76 & \\
\hline $\begin{array}{l}\text { TAG } \\
4 \text { weeks } \\
8 \text { weeks } \\
12 \text { weeks }\end{array}$ & $\begin{array}{l}3.54 \\
3.43 \\
3.44\end{array}$ & $\begin{array}{l}0.90 \\
0.95 \\
0.89\end{array}$ & $\begin{array}{l}75 \\
73 \\
77\end{array}$ & $P<0.001$ \\
\hline $\begin{array}{l}\text { SPE } \\
4 \text { weeks } \\
8 \text { weeks } \\
12 \text { weeks }\end{array}$ & $\begin{array}{l}3 \cdot 10 \\
3 \cdot 12 \\
3 \cdot 14\end{array}$ & $\begin{array}{l}0.88 \\
0.98 \\
0.90\end{array}$ & $\begin{array}{l}76 \\
77 \\
79\end{array}$ & \\
\hline
\end{tabular}

SPE, sucrose polyester; TAG, triacylglycerol.

${ }^{*} P$ values refer to difference between concentrations after 12 weeks on TAG or SPE diets.

$20-40 \mathrm{~g}$ taken in $4-8$ exchanges of $5 \mathrm{~g}$. The majority of subjects were successful in maintaining an adequate intake and only one was withdrawn because of persistently inadequate fat consumption. The mean SPE consumption was $23.7 \mathrm{~g} / \mathrm{d}$ during period 1 and $24 \mathrm{~g} / \mathrm{d}$ during period 2 . In studies of chronic feeding of SPE performed by other investigators the amount of SPE consumed each day has varied from 20-36 g/d (Jones et al. 1991; Rolls et al. 1992). Thus the amount of SPE consumed was comparable with previous studies, with the added advantage that the SPE was distributed in a much wider range and variety of foods than in others where it was generally presented as a single item such as crisps or biscuits. Subjects were not able to distinguish SPE-containing foods from the control.

Dietary analysis showed that the total fat consumption was significantly reduced following 3 months on SPE
Table 5. Effect of sucrose polyester-plasma carotenoids

\begin{tabular}{llll}
\hline Carotenoid & Mean & SD & $P$ value \\
\hline Lutein & & & $P<0.001$ \\
SPE diet & 0.24 & 0.10 & \\
TAG diet & 0.34 & 0.14 & \\
$\beta$-cryptoxanthin & & & \\
SPE diet & 0.14 & 0.11 & \\
TAG diet & 0.23 & 0.14 & \\
Lycopene & & & \\
SPE diet & 0.28 & 0.18 & \\
TAG diet & 0.48 & 0.25 & \\
$\alpha$-Carotene & & & \\
SPE diet & 0.06 & 0.03 & \\
TAG diet & 0.08 & 0.05 & \\
$\beta$-Carotene & & & \\
SPE diet & 0.26 & 0.16 & \\
TAG diet & 0.43 & 0.26 & \\
Cis- $\beta$-carotene & & & \\
SPE diet & 0.03 & 0.02 & \\
TAG diet & 0.05 & 0.04 & \\
\hline
\end{tabular}

SPE, sucrose polyester; TAG, triacylglycerol.

(Table 3). As the reduction was greater in the consumption of saturated fat, the $\mathrm{P}: \mathrm{S}$ ratio increased. More surprising was the lack of any detectable difference in total energy intake between the two diets. As there was a significant change in the energy intake of volunteers between the first 3-month period of the study and the second (presumably due to seasonal factors), SPE and control were compared in the first period alone and no difference in energy intake was observed. Dietary assessments were only performed at the end of the 3-month feeding periods and so no data are available for any changes in energy intake which might have occurred within the feeding period. The body weight of volunteers was unchanged after 12 weeks on SPE foods, although there was a slight increase in the mean body weight after 12 weeks on control. This is in keeping with the lack of any significant change in energy consumption during the study.

The majority of the volunteers had no difficulty in eating SPE foods and none suffered any severe adverse effects. Those who withdrew usually did so for social reasons (e.g. moving house). Many, however, noted changes in their

Table 6. Effect of sucrose polyester on faecal short-chain fatty acids

\begin{tabular}{lrrrr}
\hline Short-chain fatty acid & Mean & SD & $n$ & $P$ value \\
\hline Acetic acid & & & & \\
$\quad$ Admission & 128.74 & 67.93 & 76 & \\
$\quad$ TAG diet & 107.32 & 62.63 & 76 & $P<0.02$ \\
$\quad$ SPE diet & 87.67 & 60.11 & 75 & \\
Proprionic & & & & \\
$\quad$ Admission & 64.14 & 39.29 & 76 & \\
TAG diet & 58.36 & 35.74 & 76 & $P<0.02$ \\
SPE diet & 48.01 & 32.63 & 75 & \\
Isobutyric & & & & \\
Admission & 2.89 & 2.86 & 76 & \\
$\quad$ TAG diet & 1.86 & 1.54 & 76 & $P<0.02$ \\
SPE diet & 1.52 & 2.10 & 75 & \\
\hline
\end{tabular}

SPE, sucrose polyester; TAG, triacylglycerol. 
bowel habit. Studies on the effects of short-term administration of SPE to healthy subjects (Kelly \& Hunter, 1996) showed that a drink containing $50 \mathrm{~g}$ SPE accelerated gastric emptying, and slowed small bowel transit, but tended to increase WGTT and faecal weight. When the SPE was taken with varying amounts of natural TAG (Aggarwal et al. 1993) these changes in transit time and faecal weight were not apparent, presumably because the TAG present stimulated release of gut hormones such as cholecystokinin, motilin and enteroglucagon whose release is much reduced after ingestion of SPE alone (Kelly \& Hunter, 1996). The effect of long-term feeding of foods containing SPE on bowel function has not been studied in detail until now. Two reports whose main focus was on the effects of SPE in reducing plasma cholesterol stated that frequency of bowel movement was normal even after $50 \mathrm{~g}$ SPE/d, and no diarrhoea occurred (Fallat et al. 1976; Glueck et al. 1979). Bergholz et al. (1991) claimed that controlled clinical studies in over 2000 subjects showed no statistical difference in gastrointestinal symptoms after SPE feeding for single or multiple days, but no detailed results or references were provided.

These findings are in marked contrast to those of the present study. Minor upsets in bowel function are very common in the general population, and may affect as many as one-third of people. When these occur with no evidence of underlying disease, patients are usually said to suffer from irritable bowel syndrome. This is not a homogenous group, as irritable bowel syndrome may be caused by a number of factors including stress and food intolerance (Hunter, 1991). Volunteers underwent a medical examination before admission to the present study. A careful assessment of baseline symptoms was made and any subjects suffering gastrointestinal symptoms were excluded.

Bowel frequency in subjects consuming SPE was significantly increased with a median of 10 stools/week compared with 7/week on TAG. Such an increase is of little importance but urgent calls to stool, a much more distressing symptom, was reported in approximately $30 \%$ of subjects on SPE but only $10 \%$ of controls. Anal leakage of SPE oil was a problem occurring in $7 \cdot 2 \%$ on SPE, and anal leakage and abdominal pain were both significantly increased at week 8 when compared with controls. Subjective assessment of increased flatulence was reported in two-thirds of subjects on SPE. Most of these changes occurred equally at 4, 8, and 12 weeks. Faecal weights were also significantly raised when volunteers were taking SPE, and WGTT were reduced. The reason for the discrepancy from previous reports probably relates to the trial designs. In the present study, subjects were carefully studied, double-blind, over a 3-month period and using a standardized questionnaire. Their bowel function on SPE foods was compared with that on TAG foods. Under these stringent conditions it is clear that SPE significantly affects bowel function, although it is possible that it might not do so in smaller doses such as those used in snack items. Confusion with irritable bowel syndrome could therefore arise in subjects eating foods containing SPE, and might lead to significant expense in unnecessary medical investigation and treatment.
Standard haematological and biochemical analyses showed no changes in any routine variable. However, plasma cholesterol was significantly reduced after 3 months on SPE $(4.92$ v. $5.32 \mathrm{mmol} / \mathrm{l}, P<0 \cdot 001)$. TAG was likewise reduced $(0.99$ v. $1.09 \mathrm{mmol} / 1, P<0.02)$. The reduction in cholesterol was associated with a fall in HDL $(1.34$ v. $1.39 \mathrm{mmol} / \mathrm{l}, P<0.02)$ but there was a relatively greater reduction in LDL of 3.14 v. $3.44 \mathrm{mmol} / 1, P<0 \cdot 001$ ). These effects are consistent with many previous reports in the literature reviewed by Toma et al. (1988). It is clear that daily doses of SPE above $20 \mathrm{~g}$ will reduce plasma cholesterol concentrations.

As the fat soluble vitamins $\mathrm{A}, \mathrm{D}, \mathrm{E}$ and $\mathrm{K}$ might be sequestered in the gut by SPE it seemed possible that their plasma concentrations might be reduced after SPE feeding. It proved impractical to measure vitamin $\mathrm{K}$ concentrations directly as discrepancies in the results of samples sent to an independent laboratory suggested that the methodology was unreliable. Prothrombin time, which is partially dependent on vitamin $\mathrm{K}$ concentrations, remained normal throughout the study. This is in keeping with the results of Jones et al. (1991), who examined prothrombin concentrations, clotting times and phylloquinone concentrations and discovered no effect after $25 \mathrm{~g}$ of SPE daily for 6 weeks. Likewise, no changes were discovered in the plasma concentrations of vitamins $\mathrm{A}$ and D. A significant difference detected between the two feeding periods in 25-hydroxycholecalciferol was probably seasonal as no difference was detected between SPE and control diets. Cholecalciferol may be synthesized in the skin under the influence of u.v. light. Jones et al. (1991) performed a study of the effects of SPE on vitamin D absorption and avoided the effect of sunlight by supplementing the diet with ergocalciferol (vitamin $\mathrm{D}_{2}$ ), which is not synthesized naturally in the human body. Volunteers consumed $20 \mathrm{~g}$ of SPE or TAG daily for 6 weeks and it was found that the concentration of 25-hydroxyergocalciferol was $19 \%$ lower in subjects given SPE than in the controls. Clearly SPE has the propensity to reduce vitamin $\mathrm{D}$ absorption from the gut.

Vitamin $\mathrm{E}$ is a less polar compound than the other fatsoluble vitamins and is therefore more likely to be poorly absorbed in the presence of SPE. This was confirmed in the present study, where the mean concentration after SPE was $11.66 \mathrm{mg} / \mathrm{l}$ compared with $13.51 \mathrm{mg} / \mathrm{l}$ on the control diet. In the plasma, vitamin $\mathrm{E}$ is carried in lipoproteins and its concentration is therefore related to total lipid concentration. When vitamin $\mathrm{E}$ concentrations were adjusted for cholesterol concentration they were still found to be lower after SPE feeding. However, the levels recorded in the SPE volunteers remained within the normal range and no clinical ill-effects were detected.

The $15 \%$ difference in plasma concentrations of plasma vitamin E in subjects eating $20 \mathrm{~g}$ SPE daily agrees well with previous reports. Addition of $62 \mathrm{~g}$ daily of SPE to the diet resulted in a fall of $24 \%$ in vitamin E (Crouse \& Grundy, 1979), and in a further study, lower doses of SPE such as 8 and $16 \mathrm{~g}$ daily had little effect (Mellies et al. 1983). Plasma carotenoid concentrations found in subjects at the start of the present study were similar to those previously reported for the British population (Thurnham \& Flora, 1988). It was only possible to measure six carotenoids but over 600 have 
been characterized in nature. Profound falls were seen in all carotenoids measured (Table 6). The concentrations were restored promptly in those volunteers who were studied after a return to a normal diet. Since this initial work was completed a further study has confirmed the effects of SPE on plasma carotenoid concentration. As little as $3 \mathrm{~g}$ of SPE daily was sufficient to reduce concentrations of $\beta$-carotene and lycopene (Westrate \& van het Hof, 1995).

The role of carotenoids in human physiology is still poorly understood. In recent years it has become apparent that diets low in fruit and vegetables are associated with an increased risk of cancer (Hennekens, 1986) and cardiovascular disease (Gaziano et al. 1990). Epidemiological and experimental evidence exists that fruit and vegetables may reduce the risk of certain cancers and prospective studies have shown that healthy adults with low concentrations of $\beta$-carotene have an increased tendency to develop neoplasia over subsequent years (Connett et al. 1989). Concentrations of less than $0.25 \mu \mathrm{mol} / \mathrm{l}$ were associated with a two-fold increase in the risk of lung cancer (Wald et al. 1988). Recent trials have demonstrated, however, that supplementation with $\beta$-carotene does not provide protection from the development of cancer (Greenberg \& Sporn, 1996). Nevertheless, the epidemiological observation that individuals with higher blood $\beta$-carotene levels have lower risks of cancer and heart disease remains secure. $\beta$-Carotene is only one carotenoid amongst several hundred, and a fall in $\beta$ carotene may merely reflect similar changes in other, possibly physiologically more active carotenoids, many of which could have anti-cancer activity. The epidemiological evidence supporting the value of diets rich in fruit and vegetables is undisputed, although its mechanism is obscure (Greenberg \& Sporn, 1996). Until further knowledge is available, it would seem prudent to avoid introducing foodstuffs into the diet which reduce the absorption of potentially beneficial substances from plants.

After 3 months on SPE faecal weight increased significantly and WGTT was reduced. These are presumably effects of undigested SPE appearing in the stools as well as other fluids and food residues carried with it. There may also be less time for the breakdown of food residues by bacterial fermentation in the colon. This results in the passage of more frequent and looser stools and is a factor in the gastrointestinal symptoms already discussed.

Although no effect of SPE was discovered on the faecal concentrations of bile acids and steroids, SCFA were affected by SPE, with acetic, proprionic and isobutyric acids all being significantly reduced. SCFA are produced by the fermentation of complex carbohydrates and are usually absorbed rapidly into the bloodstream, the concentration in the faeces usually being inversely related to the transit time. As transit times are reduced by SPE, it was surprising to find that SCFA concentrations were reduced, but this could have represented a dilution effect in view of the increased weight of faeces.

Each volunter underwent a specialized test in the course of the SPE trial. No changes were discovered in intestinal permeability, small-bowel or rectal histology, bile salt retention, fractional $\mathrm{Ca}$ absorption or rectal prostaglandin production after SPE. As studies in laboratory rats had suggested that SPE produced an increase in the size of the caecum and a reduction in liver weight, hepatic function was further investigated. Routine liver-function tests in volunteers in the present study had been unchanged and urinary D-glucaric acid excretion, an indirect index of hepatic microsomal activity, was also unchanged on SPE. Radio-labelled aminopyrine breakdown was determined as a sensitive indicator of the activity of cytochrome P450 and related hepatic drug-metabolizing enzymes. The baseline excretion was $5 \cdot 1 \%$ of the administered dose. On the control diet this was reduced to $4.6 \%$ and on the SPE diet to $4.4 \%$. The result for SPE is significantly less than baseline but it is clear that the reduction compared with control is clinically unimportant. In summary it is unlikely that SPE affects hepatic function.

This study has demonstrated important deleterious effects of SPE which need to be carefully examined before this product is made available for widespread long-term consumption in a broad range of foods.

\section{Acknowledgements}

This work was supported by a grant from Unilever plc who also kindly supplied SPE and control products. We are extremely grateful to Professor F. A. Fairweather, W. Castenmiller, J. Van Duuren, J. van der Straaten, P. van Stratum, F. van Steen, P. Verschuren and Dr. R. N. Hill for their helpful advice, and to Dr. D. G. D. Wight for histological reports.

\section{References}

Aggarwal AM, Camilleri M, Phillips SF, Schlagheck TG, Brown ML \& Thomforde GM (1993) Olestra, a nondigestible, nonabsorbable fat: effects on gastrointestinal and colonic transit. Digestive Diseases and Sciences 38, 1009-1014.

Armitage P \& Berry G (1987) Statistical Methods for Medical Research, 2nd ed, pp. 222-226. Oxford: Blackwell Scientific Publications.

Behrens RH, Szaz KF, Northrop C, Elia M \& Neale G (1987) Radionucleide tests for assessment of intestinal permeability. European Journal of Clinical Investigation 17, 100-105.

Bergholz CM, Jandacek RJ \& Thomson ABR (1991) Review of laboratory and clinical studies of Olestra, a nonabsorbable lipid. Canadian Journal of Gastroenterology 5, 137-146.

Catignani GL \& Bieri JG (1983) Simultaneous determination of retinol and $\alpha$ tocopherol in serum or plasma by liquid chromatography. Clinical Chemistry 24, 708-712.

Connett JE, Kuller LH \& Kjelsberg MO (1989) Relationship between carotenoids and cancer. The multiple risk factor intervention trial (MRFIT) study. Cancer 64, 126-134.

Crouse JR \& Grundy SM (1979) Effects of SPE on cholesterol metabolism in man. Metabolism 28, 994.

Cummings JH \& Wiggins HS (1976) Transit through the gut measured by analysis of a single stool. Gut 17, 219-223.

Fallat RW, Glueck CJ, Lutmer R \& Mattson FH (1976) Short-term study of sucrose polyester, a nonabsorbable fat-like material as a dietary agent for lowering plasma cholesterol. Clinical Nutrition 29, 1204-1215.

Gaziano JM, Manson JE, Ridker PM, Buring JE \& Hennekens CH (1990) Beta carotene therapy for chronic stable angina. Circulation 82, 111-201.

Glueck CJ, Hastings MM, Allen C, Hogg E, Baehler L, Gartside PS, Phillips D, Jones M, Hollenbach EJ, Braun B \& 
Anastasia JV (1982) Sucrose polyester and covert caloric dilution. American Journal of Clinical Nutrition 35, 1352-1359.

Glueck CJ, Mattson FF \& Jandacek RJ (1979) The lowering of plasma cholesterol by sucrose polyester in subjects consuming diets with 800,300 or less than $50 \mathrm{mg}$ of cholesterol per day. American Journal of Clinical Nutrition 32, 1636-1644.

Greenberg ER \& Sporn MB (1996) Antioxidant vitamins, cancer, and cardiovascular disease. New England Journal of Medicine 334, 1189-1190.

Grundy SM, Ahrens EH Jr \& Miettinen TA (1965) Quantitative isolation and gas liquid chromatographic analysis of total fecal bile acids. Journal of Lipid Research 6, 397-410.

Hennekens CH (1986) Micronutrients and cancer prevention. New England Journal of Medicine 315, 1288-1289.

Hepner EW \& Vesell ES (1975) Quantitative assessment of hepatic function by breath analysis after oral administration of C14 aminopyrine. Annals of Internal Medicine 83, 632-638.

Hollis BW \& Frank NE (1985) Solid phase extraction system for vitamin D and its major metabolites in human plasma. Journal of Chromatography 343, 43-50.

Hunter JO (1991) Food intolerance and the irritable bowel syndrome. In Irritable Bowel Syndrome, pp. 203-219 [NW Read, editor] London: Blackwell Scientific Publications.

Jandacek RJ (1984) Studies with sucrose polyester. International Journal of Obesity 8, 13-21.

Jones DY, Miller KW, Koonsvitsky BP, Ebert ML, Lin PYT, Jones MB \& DeLuca HF (1991) Serum 25-hydroxyvitamin D concentrations of free-living subjects consuming Olestra. American Journal of Clinical Nutrition 53, 1281-1287.

Juno K \& Pergande M (1984) Glucaric acid. In Methods of Enzyme Analysis. 3rd ed., pp. 228-238. Deerfield Beach, Florida: Weinheim.

Kelly SM \& Hunter JO (1996) The effect of a non-absorbable fat substitute, sucrose polyester, on gastrointestinal function. Alimentary Pharmacology and Therapeutics 10, 715-720.

MacFarlane GT, Cummings JH, Allison C (1986) Protein degradation by human intestinal bacteria. Journal of General Microbiology 132, 1647-1656.

Manku MS, Horrobin DF, Huang YS \& Morse N (1983) Fatty acids in plasma and red cell membranes. Lipids 18, 906-910.

Mellies MJ, Jandacek RJ \& Taulbee JD (1983) A double-blind, placebo-controlled study of sucrose polyester in hypercholesterolemic out-patients. American Journal of Clinical Nutrition 37, 339-346.

Mellies MJ, Vitale C, Jandacek RJ, Lamkin GE \& Glueck CJ (1985) The substitution of sucrose polyester for dietary fat in obese, hypercholesterolemic out-patients. American Journal of Clinical Nutrition 41, 1-12.

Nyhlin H, Merrick MV, Eastwood MA \& Bryden WG (1983) Evaluation of ileal function using SeHCAT. An initial assessment. Gastroenterology 84, 63-68.

Pecker RR, Bammi A, Barger-Lux MJ \& Heaney RP (1988) Calcium absorbability from milk products, an imitation milk and calcium carbonate. American Journal of Clinical Nutrition 47, 93-95.

Rampton DS, Sladen JE, Bhakoo KK, Heinzelmann DI \& Youlton JK (1980) Rectal mucosal PGE release and electrolyte transport in ulcerative colitis. Prostaglandin and Thromboxane Research 8, $1621-1625$.

Rolls BJ, Pirraglia PA, Jones MB \& Peters JC (1992) Effects of Olestra, a noncaloric fat substitute, on daily energy and fat intakes in lean men. American Journal of Clinical Nutrition 56, 84-92.

Thurnham DI \& Flora PS (1988) Do higher vitamin A requirements in men explain the difference between the sexes in plasma provitamin A carotenoids and retinol. Proceedings of the Nutrition Society 47, 181A.

Thurnham DI, Smith E, Flora PS (1988) Concurrent liquid chromatography assay of retinol, $\alpha$ tocopherol, $\beta$ carotene, $\alpha$ carotene, lycopene and $\beta$ cryptoxanthene in plasma with tocopherol acetate as internal standard. Clinical Chemistry 34, 377388.

Toma RB, Curtis DJ \& Sobotor C (1988) Sucrose polyester: Its metabolic role and possible future applications. Food Technology. January 1988, pp. 93-95.

Wald NJ, Thompson SG, Densem JW, Boreham J \& Bailey A (1988) Serum beta-carotene and subsequent risk of cancer: Results from the BUPA study. British Journal of Cancer 57, 428-433.

Westrate JA \& van het Hof KH (1995) Sucrose polyester and plasma carotenoid concentrations in healthy subjects. American Journal of Clinical Nutrition 62, 591-597. 